\title{
Root tensile strength of 3 typical plant species and their contribution to soil shear strength; a case study: Sasumua Backslope, Nyandarua District, Kenya
}

\author{
Osano Simpson Nyambane ${ }^{1}$, Sixtus Kinyua Mwea $^{2}$ \\ ${ }^{1}$ Department of Civil and Construction Engineering, University of Nairobi, Kenya \\ ${ }^{2}$ Department of Civil and Construction Engineering, University of Nairobi, Kenya
}

\begin{abstract}
The effect of root reinforcement depends on the morphological characteristics of the root system, the tensile strength of individual roots, the soil-root cohesive strength, and the distribution of the root system in the soil. This research looks into Sasumua Backslope in Kenya, where a great deal of erosion is responsible for large soil losses. Shallow mass movements are evident throughout the slope. Root reinforcement effect of nine typical species was assessed, using Wu et al. (1979) model. The plant species comprised of shrubs (Atriplex halimus), grasses (Pennisetum clandistenum and Themeda triandra), and tree ferns (Asparagus species). Physical counting of roots per depth class was conducted to obtain root area ratio (RAR) values of the individual species. For each species, single root specimens were sampled and tested for tensile tests in the laboratory using the Hounsfield Tensometer apparatus. Maximum RAR values were located within $0.1 \mathrm{~m}$ for all the species, with maximum rooting depth of $0.7 \mathrm{~m}$ for fern tree. Shrubs species showed high RAR values between $0.1-0.3 \mathrm{~m}$ depth. Tensile force increases with diameter. Generally shrubs break at high tensile force (160 N maximum), followed by tree ferns (maximum $90 \mathrm{~N}$ ) and lastly grass (maximum $75 \mathrm{~N}$ ). Root tensile strength decreases with increasing root diameter, and follows a power law equation of the form $f(x)=a x^{k}$. Generally, tensile strength can be well predicted by root diameter. The maximum root tensile strength values recorded was $39 \mathrm{~N} / \mathrm{mm}^{2}$ for grass. The results presented in this paper contribute to expanding the knowledge on root resistance behavior and on root density distribution within the soil. The studied location has allowed the implementation of soil-root reinforcement models initially used by $\mathrm{Wu}$ et al. (1979) and the evaluation of the vegetation contribution to soil stability.
\end{abstract}

Keywords: Root area ratio (RAR); root tensile strength; root tensile force; root system. 


\section{INTRODUCTION}

Roots are equal in importance to leaves as the life support system for plants and thus for all life in terrestrial ecosystems (Arora, 1991). The recognition of different types of roots is important because these can have different functions. Most plants produce one or more orders of lateral root branches. Brundrett et al. (1985) demonstrated that different orders of roots vary in their thickness, branching patterns, growth rates, capacity for secondary growth, lifespans, structural features and that most plants produce one or more orders of lateral root branches. Higher order lateral roots are generally thinner, shorter and don't live as long as those of lower orders.

\section{Root growth}

Young roots with living epidermal cells and root hairs, are often considered to be responsible for most direct nutrient uptake (Lyr \& Hoffmann, 1967). Young roots can be recognized by observing the distance of xylem and endodermis cell maturation from the root tip. Roots which have stopped growing have mature xylem vessels at their apex. These features are readily apparent after roots have been cleared and stained (O'Brien \& McCully, 1981).

Crop plants typically have roots which elongate $1 \mathrm{~cm}$ or more in a day (Russell, 1977), while roots of plants in a natural ecosystem may grow $1 \mathrm{~mm}$ or less a day (Brundrett, 1991).

\section{Roots as slope reinforcement material}

According to Wu et al. (1979), the effect of vegetation roots on soil shear strength can be taken as part of the cohesive strength component of the soil-root system. Assuming that the phreatic surface is at the soil surface and the location of the potential shear plane is $\mathrm{z}$ distance below the soil surface, the safety factor (the minimum possible shear strength / the maximum possible shear stress) for a vegetated infinite slope is given by equation below;

$\mathrm{SF}=\frac{\left[c^{\prime}+\Delta c+\left(z \cos ^{2}(\alpha)\left(\gamma_{\text {sat }}-\gamma_{w}\right)+w_{t} \cos \alpha\right) \tan \phi^{\prime}\right]}{\left[z \gamma_{\text {sat }} \cos \alpha \sin \alpha+w_{t} \sin \alpha\right]}$ ...Equation 1

where $c^{\prime}$ and $\phi^{\prime}$ are the effective soil strength parameters, $\Delta c$ is the increased cohesion due to tree roots, $\alpha$ is the slope angle, $w_{t}$ is the vegetation surcharge (weight / unit area), $\gamma_{\text {sat }}$ is the saturated unit weight of soil and $\gamma_{w}$ is the unit weight of water. In order to predict the landslide threshold conditions, the soil strength parameters are estimated from the Mohr-Coulomb failure envelope derived from the peak values of a series of shear stress-displacement curves (Ekanayake et al., 1997).

\section{Soil shear strength estimation model}

The model of Wu et al. (1979) is used to estimate the increase in soil shear strength due to presence of roots. Their model assumes that roots grow vertically and act as loaded piles, so tension is exerted to them as the soil is sheared. This model was also used by De Baets et al. (2008) where they tested root tensile strength and root distribution of typical Mediterranean plant species. If the soil is rooted, the increased soil shear strength can be expressed as an additional cohesion; 
where $s$ is soil shear strength without roots $(\mathrm{kPa}), s_{\mathrm{r}}(\mathrm{kPa})$ is the shear strength of the soil with roots and $C_{\mathrm{r}}(\mathrm{kPa})$ is the increase in shear strength due to the presence of roots.

From Wu et al. (1979) model, the predicted shear strength increase from a full mobilization of root tensile strength is given by;

$\mathrm{Cr}=t_{\mathrm{R}}(\sin \theta+\cos \theta \tan \Phi)$

...Equation 3

where $\theta$ is the angle of shear distortion in the shear zone, $\Phi$ is the soil friction angle $\left(^{\circ}\right)$ and $t_{\mathrm{R}}$ is the total mobilized tensile stress of roots fibers per unit area of soil.

$\theta$ can be taken as $45^{\circ}$ and soil friction angle as $25^{\circ}$ for Sasumua soils. Then from Equation 3,

$\mathrm{Cr}=1.04 t_{\mathrm{R}}$

...Equation 4

$t_{\mathrm{R}}$ can be calculated from Equation 5 in a modified model of Wu et al. (1979) to suite our case;

$t_{R}=\frac{\sum T a}{A}$

...Equation 5

where $T$ is root tensile stress (MPa), $a$ is the root cross-sectional area $\left(\mathrm{m}^{2}\right)$ and $A$ is the reference area of soil occupied by roots $\left(\mathrm{m}^{2}\right.$, determined by the vertical projection of the above-ground biomass of the plant). $T$ was tested only for 5 roots in each species and plotted against diameter, D. From graph, $T$ was obtained for all the roots.

Reubens et al. (2009) points out that most studies on roots-reinforced soils deal with nutrient and organic matter input into the soil and only considers small diameter roots in the upper soil layers. However, in recent years the interest in understanding of the role of vegetation on stability of slopes are increased and the number of studies on this issue is increasing (Bischetti et al., 2009). In Kenya, research on stability of slope using vegetation roots is scarce, therefore the main objective of the present study is to expand the knowledge on both root strength and root density of typical plant species grown in Kenyan slopes and to evaluate their contribution to soil reinforcement of slopes.

\section{MATERIALS AND METHODS}

\section{Study Site}

Root sampling of 9 different plant species, each plant species comprising of 2-3 individual samples, took place in the Sasumua Water Treatment Backslope, situated in Njambini Division, Nyandarua District of Central Province in Kenya. Fig. 1 shows the geographical map of the research site.

Here, slopes are steep, ranging from $15^{\circ}$ to $45^{\circ}$. The length of entire slope is about $180 \mathrm{~m}$. Soils comprise of hard murram, fine grained gravels to red coffee soils. During rainy seasons, a series 
of shallow landslides occur, severely disrupting the operation of the Treatment Plant situated just downhill. Physical observations reveals that the site has a relatively thin soil mantle, underlain by a calcareous bedrock that contains discontinuities and cracks which are penetrable by roots. Fig. 2 is the photograph showing the extent of the shallow landslide and rampant gully erosion.

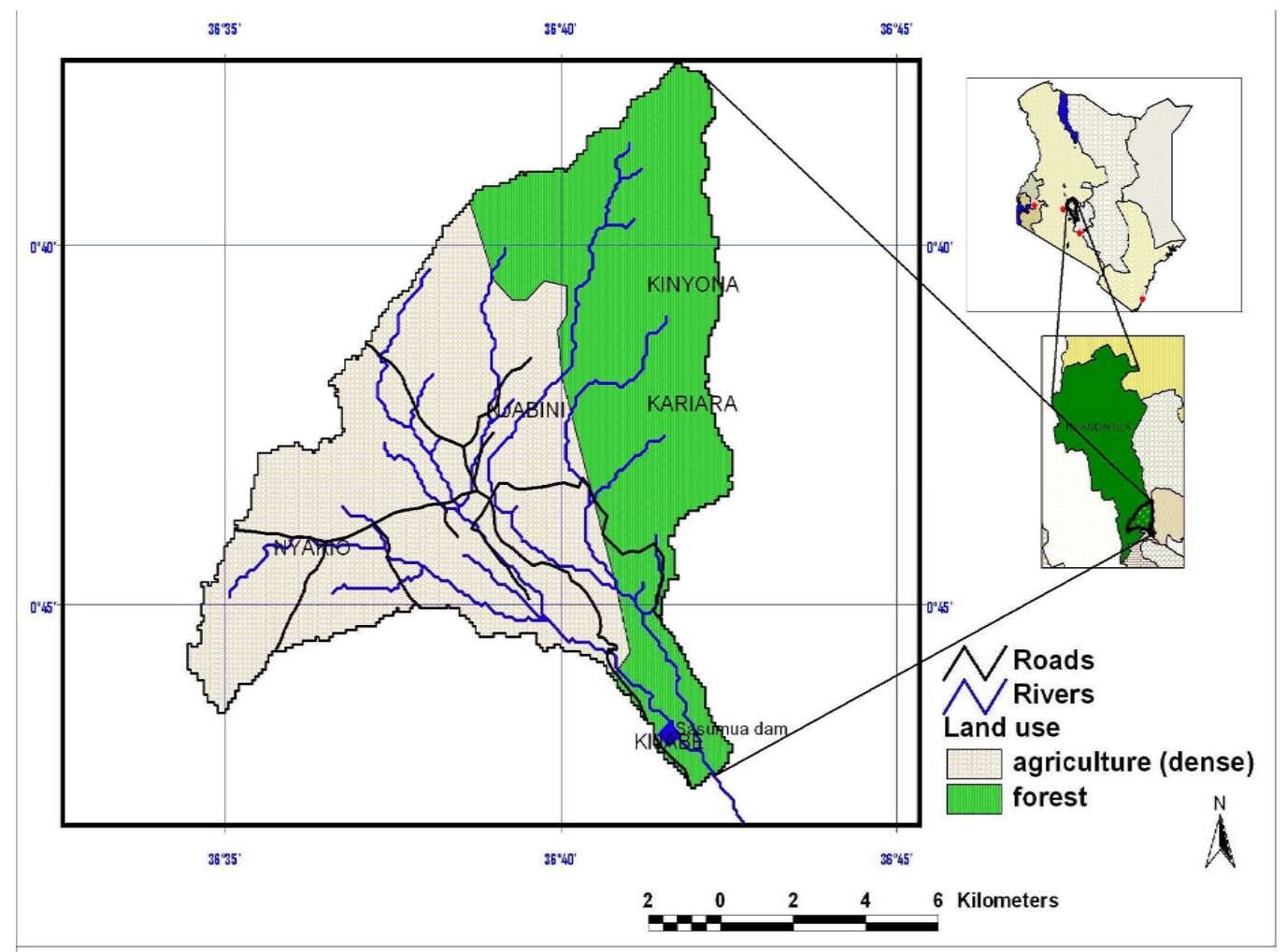

Fig. 1: Geographical map of Nyandarua District in Kenya indicating the location of Sasumua 


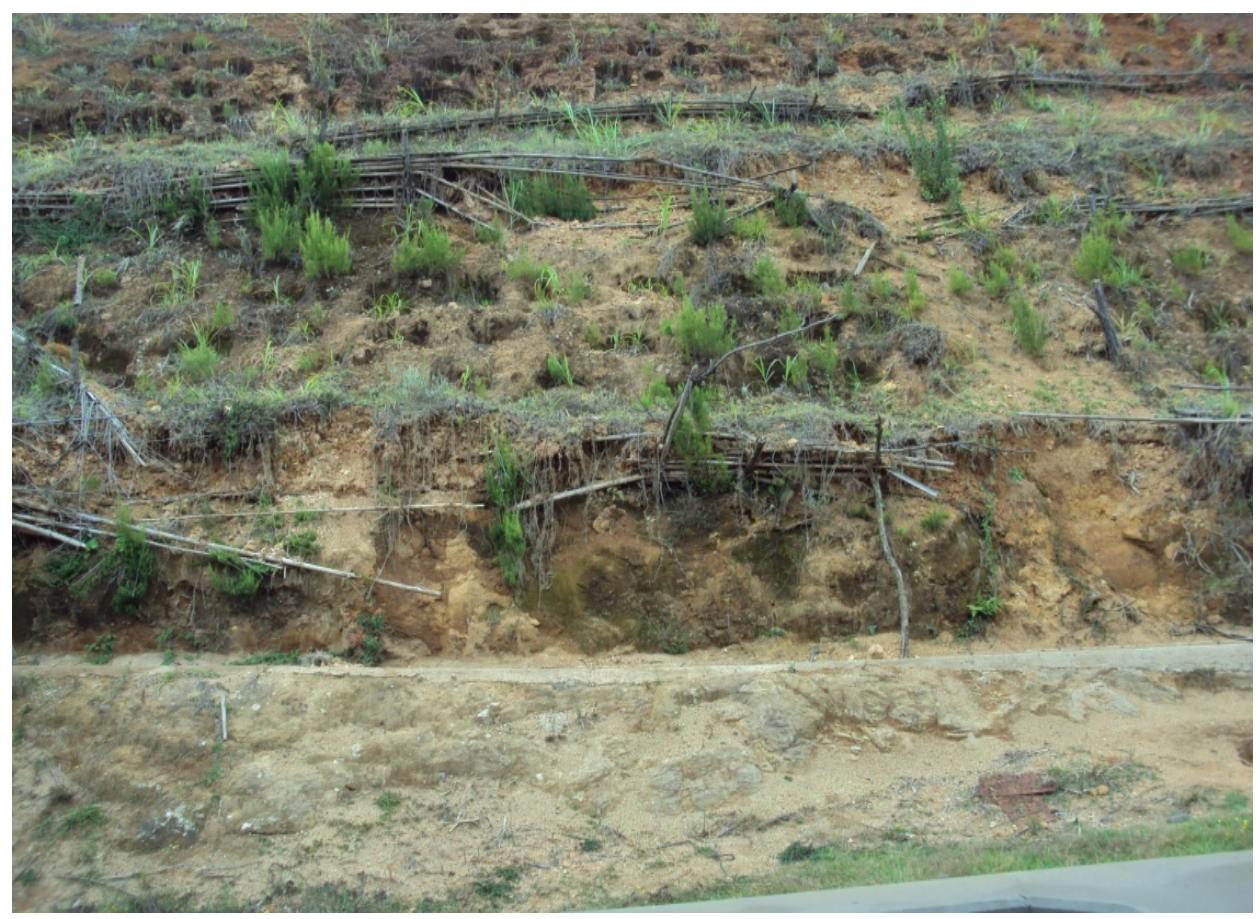

Fig. 2: Photograph of the research site showing an eroded terrain with effects of shallow landslides

\section{Sampling}

Roots were sampled for conducting tensile strength tests in the laboratory. Selection was random, and roots species having root penetration into soil of more than $0.2 \mathrm{~m}$ were excavated. This is because such species could be considered for use in erosion and landslide control measures where gully erosion is likely to occur. In Sasumua backslope, shallow landslide and gully erosion have been taking place over the years, but some sections have remained stable. Roots were excavated from stable and unstable places in equal proportions. These plant species were grasses: Kikuyu grass (Pennisetum clandistenum), and Red oats (Themeda triandra); shrubs: Saltbush (Atriplex halimus): and Tree ferns (Asparagus species). No large trees were selected for potential use in slope stability, as the weight of large trees might surcharge the slope, increasing normal and downhill force components (Gray and Sotir, 1996).

After excavation, the roots were stored in a plastic bag to preserve their moisture content. The roots were taken to a laboratory and kept in a cold room to conserve them.

Apparatus and procedure

The Hounsfield Tensometer apparatus (Fig. 3) was used to determine root tensile strength, $T$. 


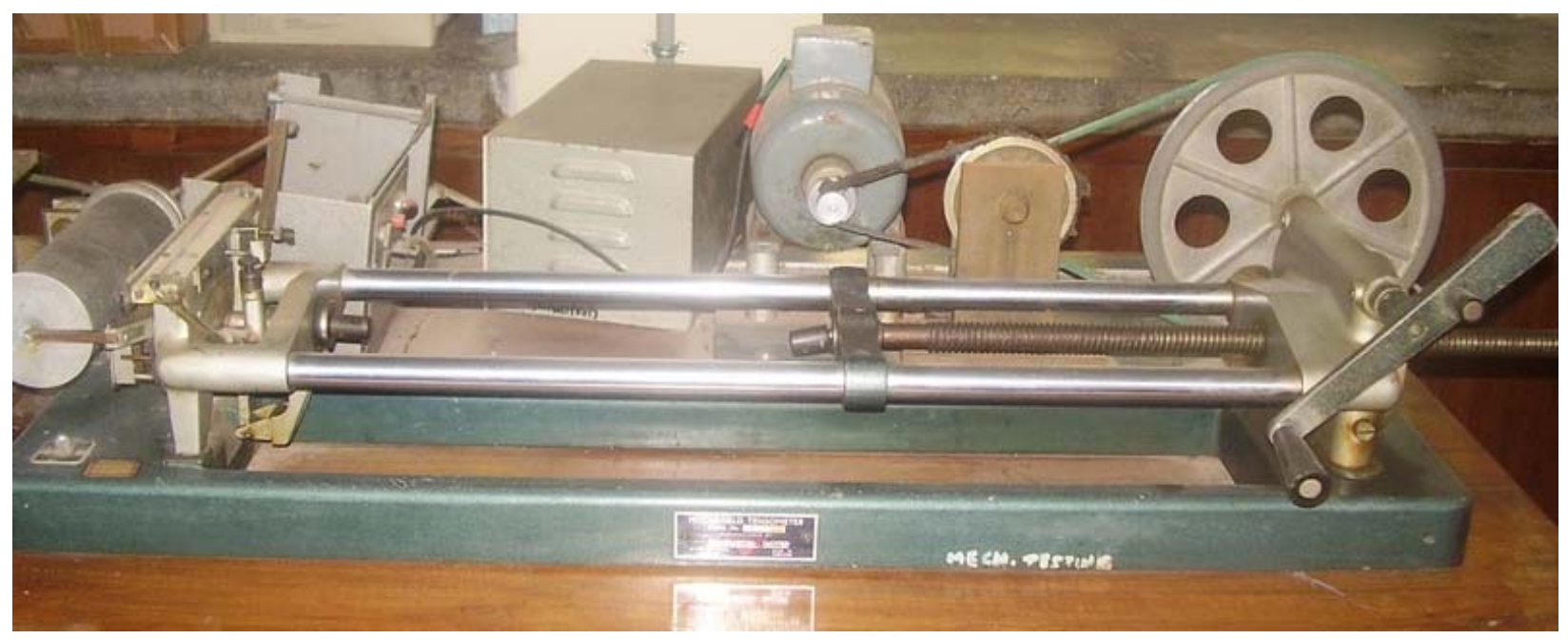

Fig. 3: The Hounsfield Tensometer Appratus

The machine is motor driven to achieve a constant rate of extension for the large extensions expected of plant roots. The standard motor drive unit (M.D.U.) consists of a cast base plate which is located at the back of the Tensometer base by two dowels. A 9" Pulley is fitted to the drive shaft on the Tensometer. The motor is controlled by a switch mounted in a small metal box at the end of a flexible cable. Forward and reverse limit switches are provided which clip on to the rear standard and stop the motor at predetermined positions of the crosshead.

The sample to be tested was clamped between two grips. Clamping is the most critical issue when measuring root strength. In our tests, the roots were clamped using wedge grips as shown in Fig. 4. They are self gripping, are quick to use, and do not have to be removed from the machine for each test. To improve the clamping and avoid slippage, fine sandpaper was attached to the grips.

Roots measuring less than $6 \mathrm{~mm}$ in diameter were selected. This is because the grips available were capable of clamping roots with diameters less than $8 \mathrm{~mm}$. Large diameters required special jaws. The length of each root was maintained at $0.1 \mathrm{~m}$ by trimming ends. Roots were clamped into entire wedge grip length in order to achieve a superior grip which could avoid slippage during testing.

After clamping the roots into wedge grips, the motor was driven manually to apply initial tension into the roots, and the mercury scale set at zero. Root diameters at either ends were taken, and the initial length of the exposed root also recorded. The motor drive unit was then put on subjecting the sample to a movement of the clamps at a constant rate of $10 \mathrm{~mm} / \mathrm{min}$., and testing commenced. Loading was recorded at every 30 seconds until failure occurred. 


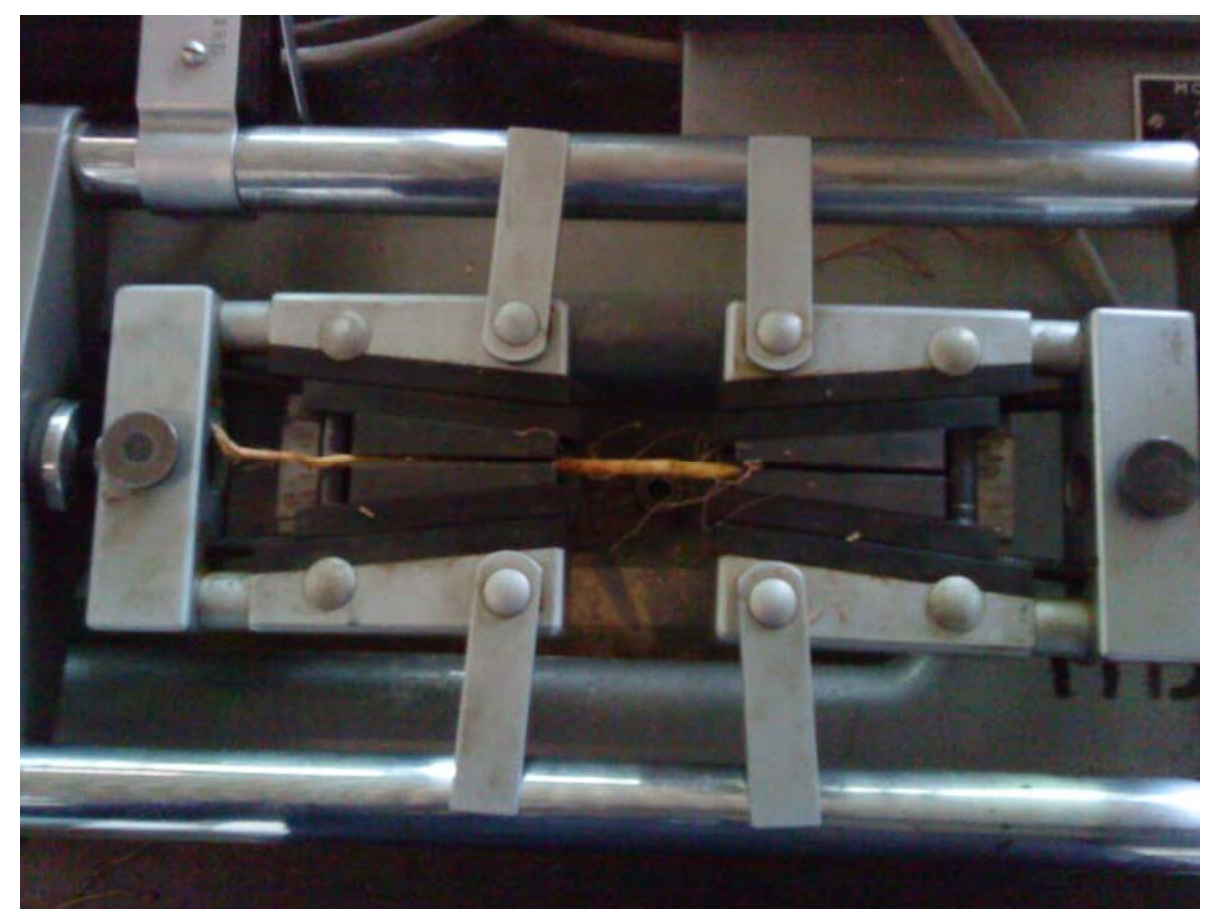

Fig. 4: Clamping of the roots using wedge grips

The elongation of the roots was recorded by simply taking the length between the grips at failure. The following formula was then used to calculate $T$ (De Baets S. et al., 2008).

$$
T=\frac{F_{\max }}{\pi\left(\frac{D^{2}}{4}\right)}
$$

where $F_{\max }$ is the maximum force $(\mathrm{N})$ needed to break the root and $\mathrm{D}$ is the mean root diameter (mm) before stretching.

Results of roots that failed at the grips were discarded as rupture occurred below their actual strength.

\section{RESULTS AND DISCUSSION}

\section{Root morphology}

Differences among plant species in morphology and patterns of growth are assumed to influence their ability to acquire resources and, consequently, their competitive ability. Comparisons of root morphology, growth rate and topology of seedlings of 9 herbaceous plant species occurring 
in early to mid-successional fields revealed significant differences among them. Tree ferns and shrubs produced longer and more branched roots than grass species. The grasses allocated proportionately more biomass to roots but do not produce deeper roots or better branching pattern. Well-developed tap roots were generally associated with deep root systems and with species developing root-borne shoots, while fasciculate roots with numerous fine roots were usually associated with species forming shoot-borne roots, but never root-borne shoots. In the studied species, shoot-rooting was related to laterally spreading root systems reaching moderate depths. Fig. $5(\mathrm{a}-\mathrm{i})$ shows the growth patterns on some of the species studied. Shrubs have a typically dense and fibrous root system. Tree ferns have a typical tap root system with branching. The general behavior of root density, in any case, is to decrease with depth.

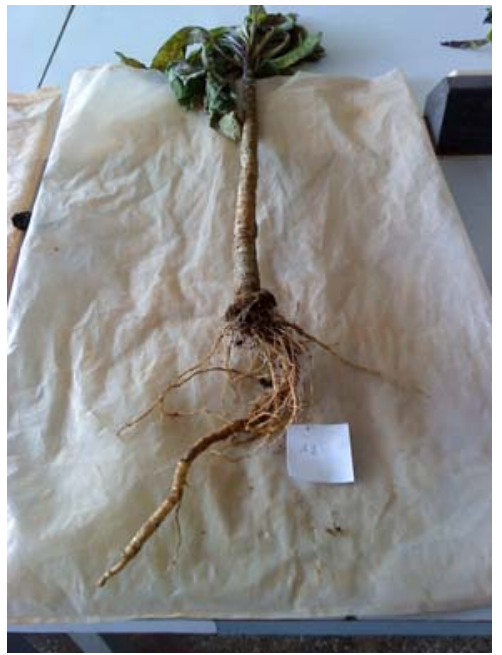

a

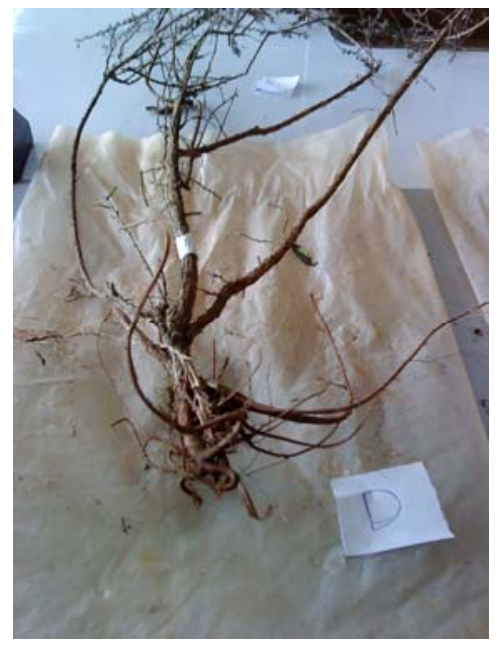

d

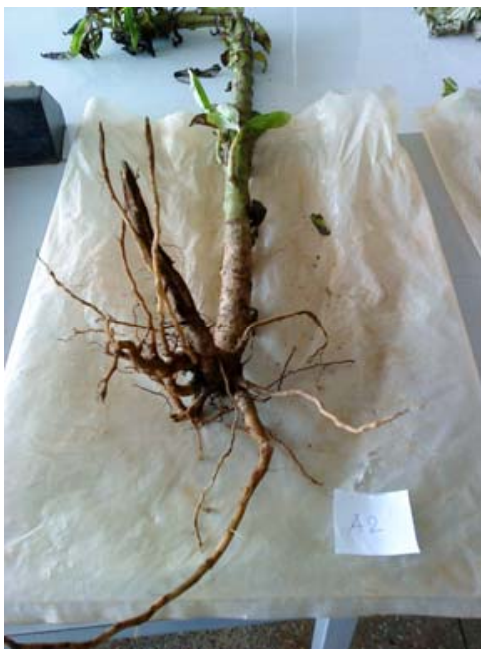

b

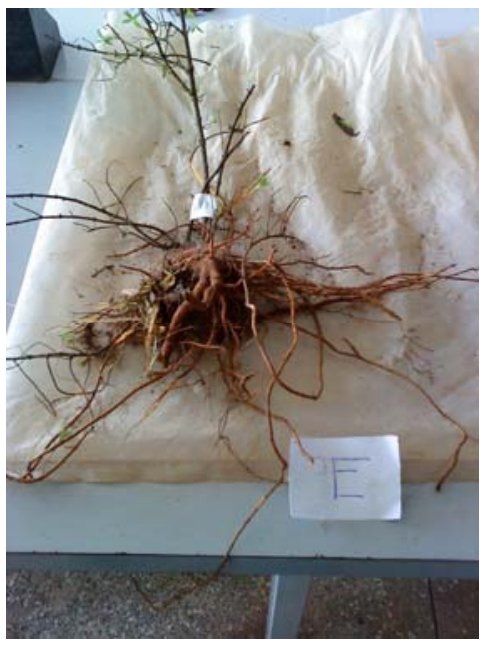

e

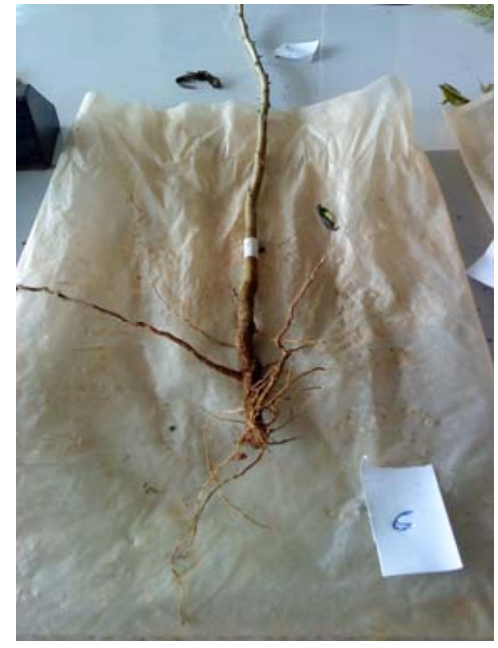

C

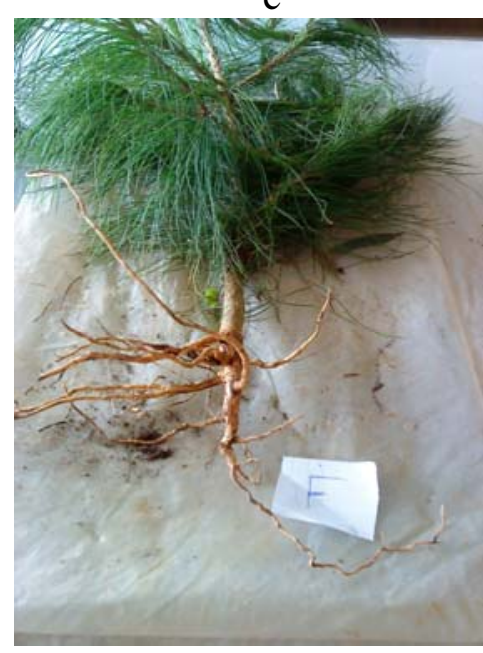

f 


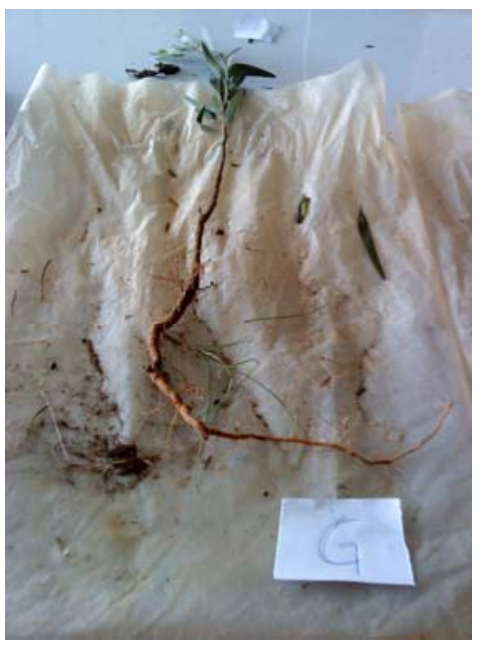

g

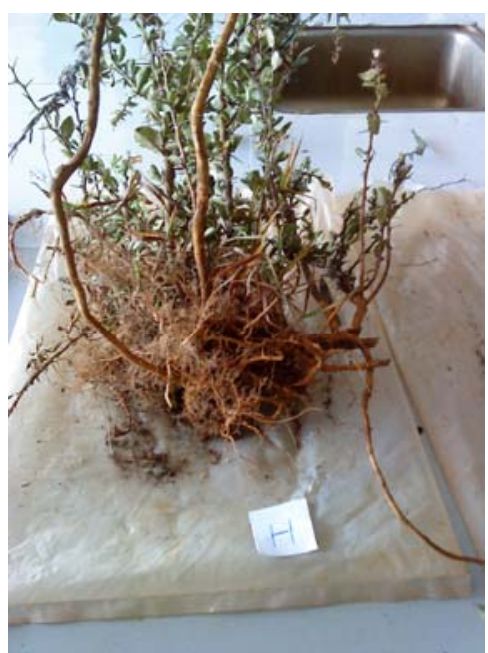

$\mathrm{h}$

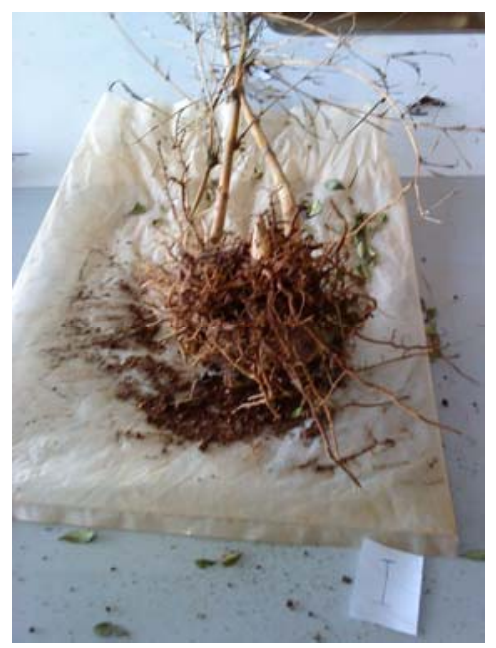

i

Fig. 5: Examples of plant species growing in Sasumua Backslope tested for tensile Root tensile strength showing the different growth patterns

As can be seen from Fig. 5, there are one or more orders of lateral root branches. Different orders of roots vary in their thickness and branching patterns. Brundrett (1991) added that roots also vary in growth rates, capacity for secondary growth, lifespans and structural features. The recognition of different types of roots is important because these can have different functions. Higher order lateral roots are generally thinner, shorter and don't live as long as those of lower orders.

The $T$ - $D$ relationships for the species tested in this study are shown in Fig. 6. It is noted that root tensile strength decreases with increasing root diameter, and follows a power law equation of the form;

$$
f(x)=a x^{k}
$$

Root tensile strength - root diameter relationship depend on plant species. Tensile strength within a species varies by root diameter.

Generally, tensile strength can be well predicted by root diameter. The maximum root tensile strength values recorded was $39 \mathrm{~N} / \mathrm{mm}^{2}$ for grass. The a and $k$ values and the $R^{2}$ values are shown in Table $1 . n$ is the number of roots tested. 
Table 1: a and $\mathrm{b}$ values and $R^{2}$ values for the power relationships for the root tensile strengths

\begin{tabular}{llllll}
\hline Vegetation type & $\begin{array}{l}\text { Diameter range } \\
(\mathbf{m m})\end{array}$ & $\mathbf{a}$ & $\mathbf{k}$ & $\mathbf{n}$ & $\boldsymbol{R}^{\mathbf{2}}$ \\
\hline Shrub & & & & & \\
& $1.2-6.0$ & 49.21 & -1.45 & 3 & 0.99 \\
& $2.4-5.2$ & 38.87 & -0.76 & 5 & 0.70 \\
& $2.2-4.5$ & 38.49 & -0.63 & 4 & 0.99 \\
& $2.2-5.1$ & 46.05 & -1.17 & 5 & 0.98 \\
\hline Grass & & & & \\
& $1.3-2.3$ & 22.45 & -1.55 & 5 & 0.79 \\
& $1.2-2.9$ & 25.53 & -0.87 & 5 & 0.98 \\
& $1.1-2.9$ & 44.08 & -1.28 & 5 & 0.98 \\
& $1.6-3.9$ & 25.53 & -1.23 & 5 & 0.97 \\
\hline Tree fern & $1.3-2.9$ & 36.72 & -0.87 & 5 & 0.97 \\
& & & & & \\
& $1.4-2.4$ & 30.5 & -1.53 & 3 & 0.94 \\
& $1.8-3.2$ & 39.29 & -0.88 & 4 & 0.95 \\
& $1.4-3.0$ & 55.86 & -1.44 & 5 & 0.99 \\
& $1.5-4.3$ & 42.66 & -1.22 & 6 & 0.98 \\
\hline
\end{tabular}

Strong roots have high $a$-values and low $k$-values and vice versa. Shrubs generally have high $a$ values, but a great variation is noted within individual plant species. Results strongly imply that shrubs species have prominent root mechanical properties and it is anticipated that these particular species have the necessary features to be outstanding slope reinforcement plants.

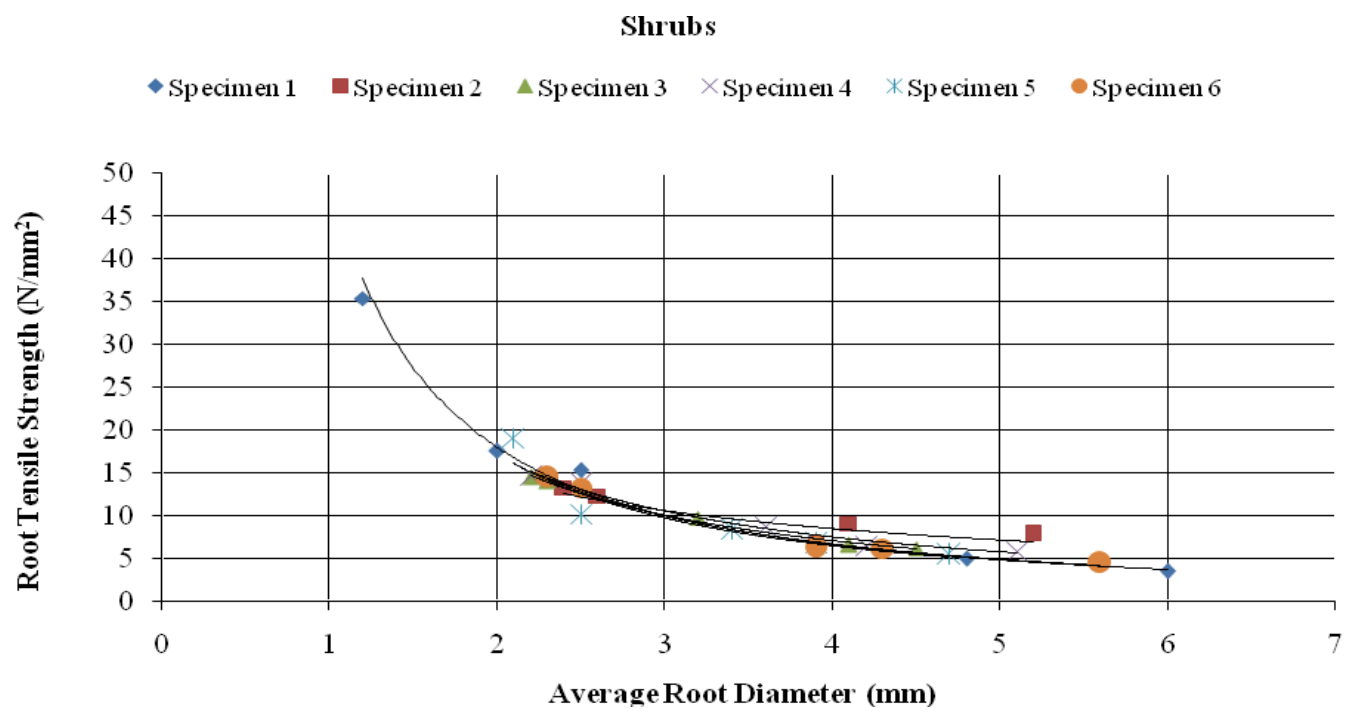



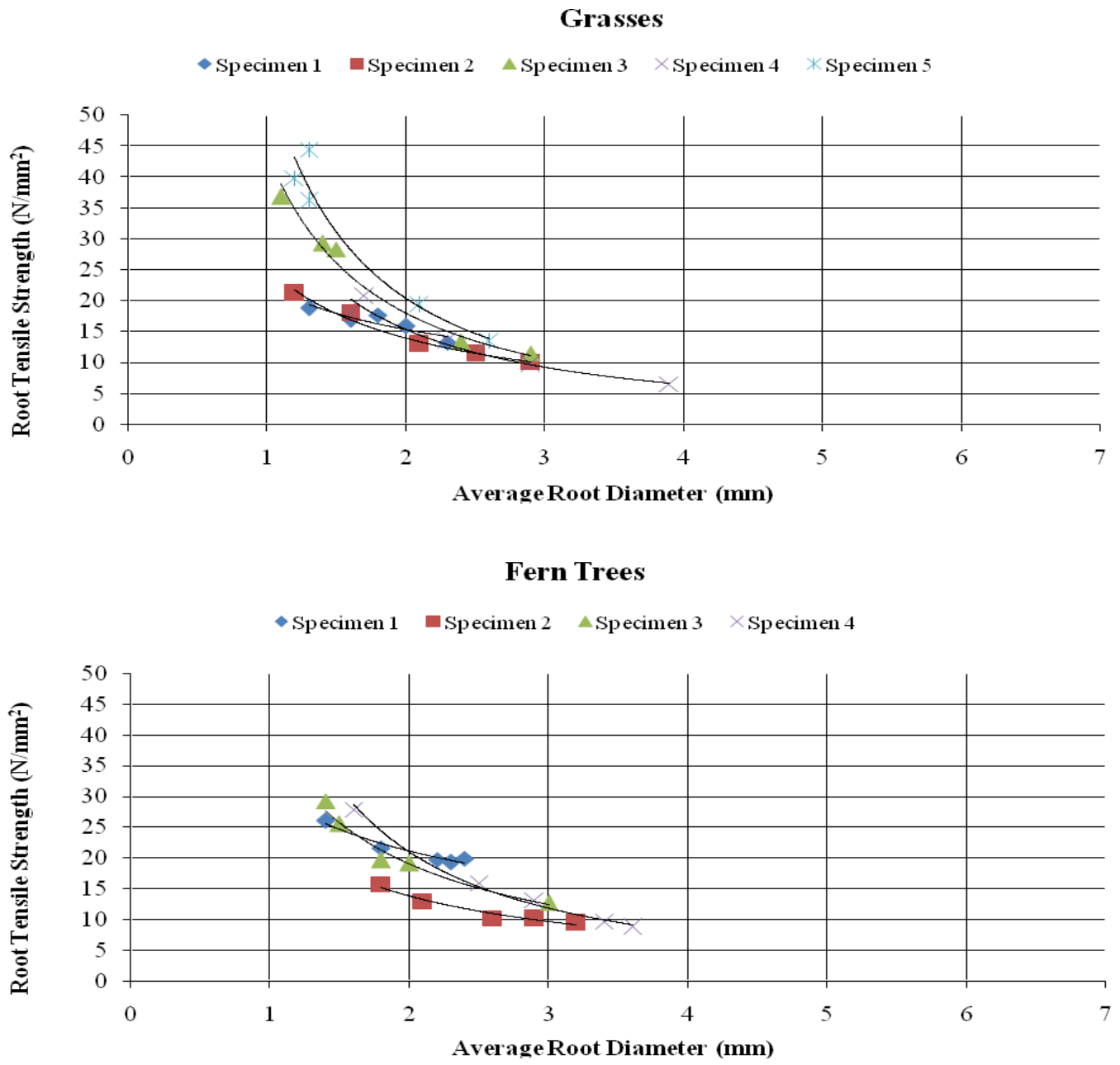

Fig. 6: T-D relationship for shrubs, grasses and tree ferns. The curves show increasing tensile strength with decreasing root diameter following power law.

\section{Root area ratio and root distribution}

Biomechanical characteristics of the root system were assessed by measuring Root Area Ratio (RAR) values and tensile strength of root specimens. RAR (the ratio of the sum of the root areas to the area of soil profile they intersect) values of the roots were obtained using profile trenching method as a function of soil depth in order to estimate root contribution to soil strength. Mean cross-sectional area occupied by roots were obtained for soil depth intervals of $0.05 \mathrm{~m}$. The number of roots at intervals of $0.05 \mathrm{~m}$ is then multiplied with the mean cross-sectional area $\left(\mathrm{m}^{2}\right)$ of a root of a certain species. This value is then divided by the horizontal cross-sectional area determined by the vertical orthogonal projection of the above-ground biomass, being our reference area. RAR or root biomass concentration as a function of soil depth is required in order to estimate root contribution to soil strength (De Baets et al., 2008). 
In order to obtain RAR values, individual roots were counted manually after the plant was uprooted from the soil. The number of roots and depth at which they occur were taken and recorded for each species. RAR values were obtained at depth increments of $0.05 \mathrm{~m}$ of all roots with diameter more than $1 \mathrm{~mm}$. The diameters of roots intersecting the soil profile were measured by a Vernier caliper.

The distribution with depth for shrubs, grasses and trees is shown in Fig. 7.

From the plot, it is observed that values of RAR show great variability with depth. Maximum RAR values were located within $0.1 \mathrm{~m}$ for all the species, with maximum rooting depth of $0.7 \mathrm{~m}$ for fern tree. Shrubs species showed high RAR values between $0.1-0.3 \mathrm{~m}$ depth. In general, vegetations growing in the Sasumua Backslope have shallow roots (maximum rot depth $0.65 \mathrm{~m}$ ) therefore unable to reinforce the soils to stop the landslide occurring at $1 \mathrm{~m}$ depths.

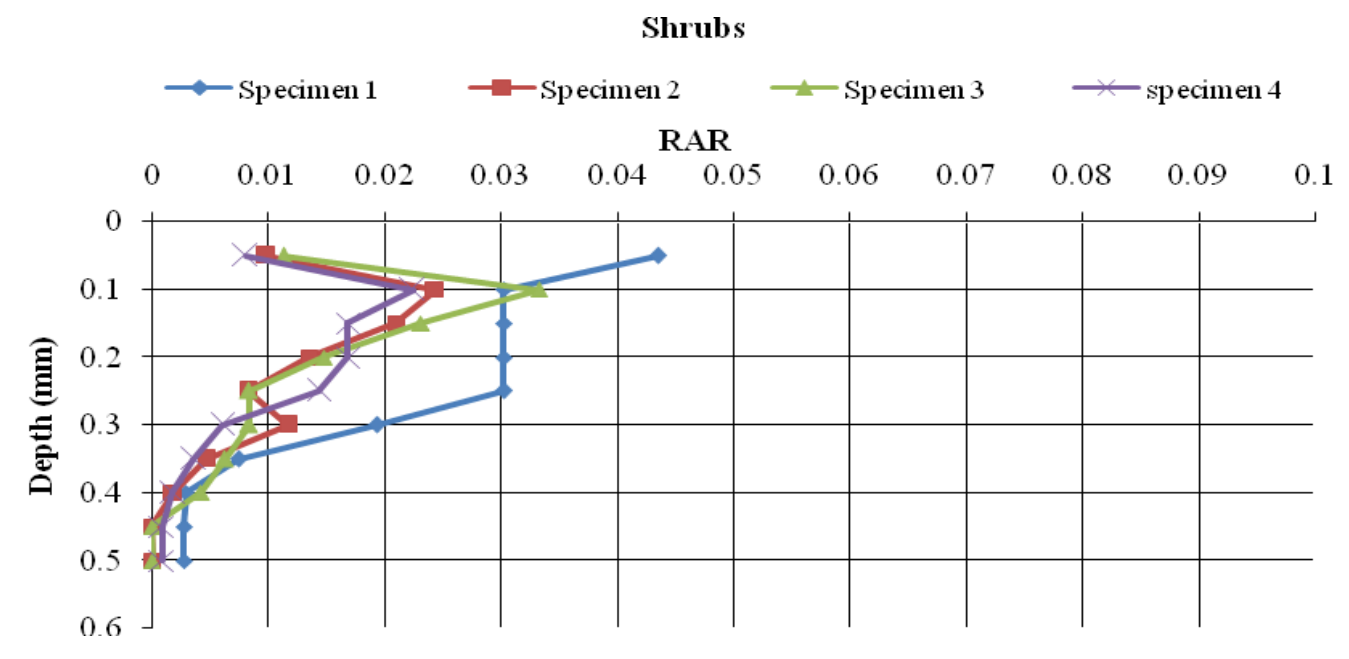



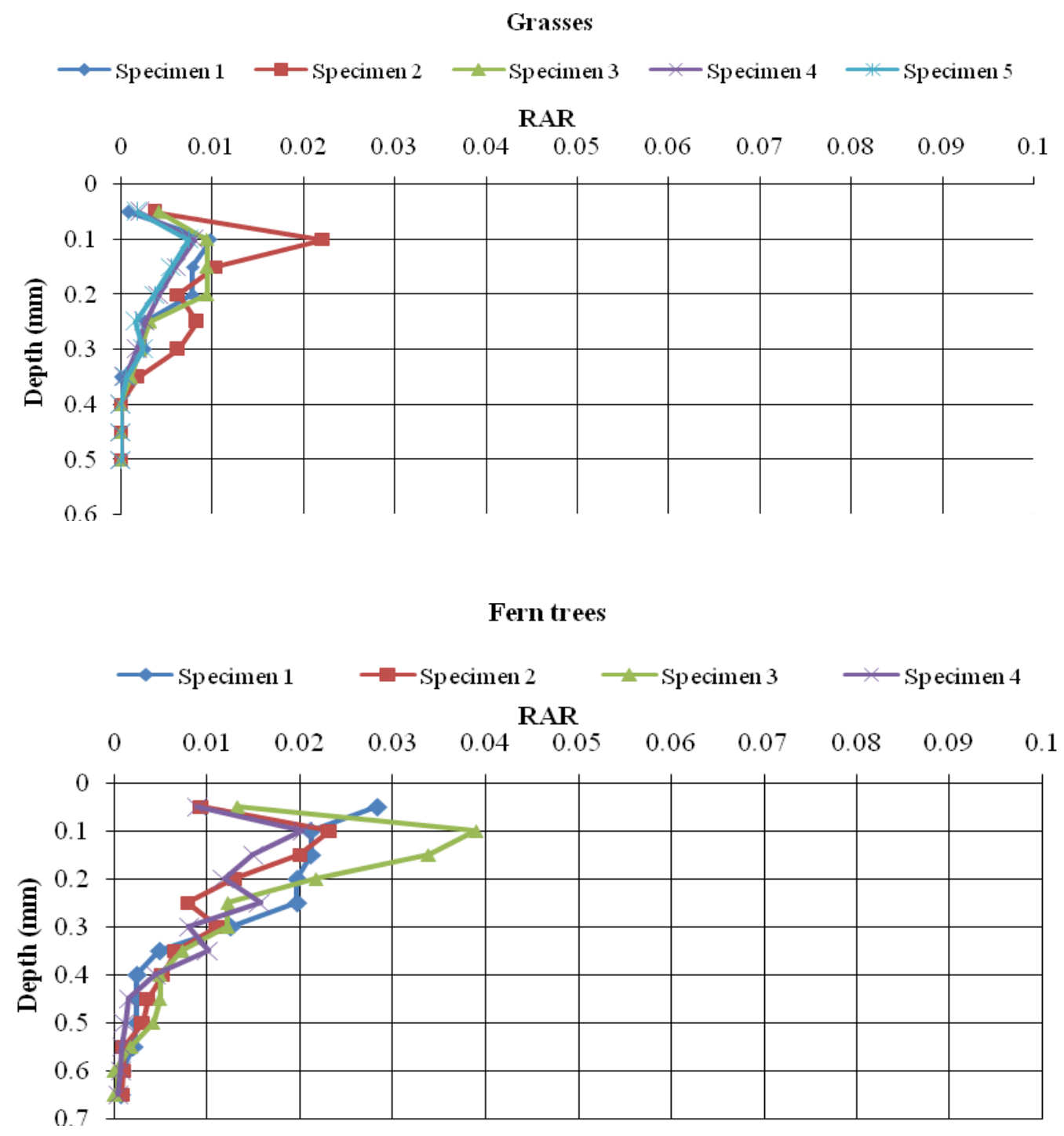

Fig. 7: Root area ratio (RAR) distribution with depth for shrubs, grasses and tree ferns

Root cohesion

Using Equation 5, the potential of soil reinforcement by roots was estimated for each species as shown in Fig. 8. 

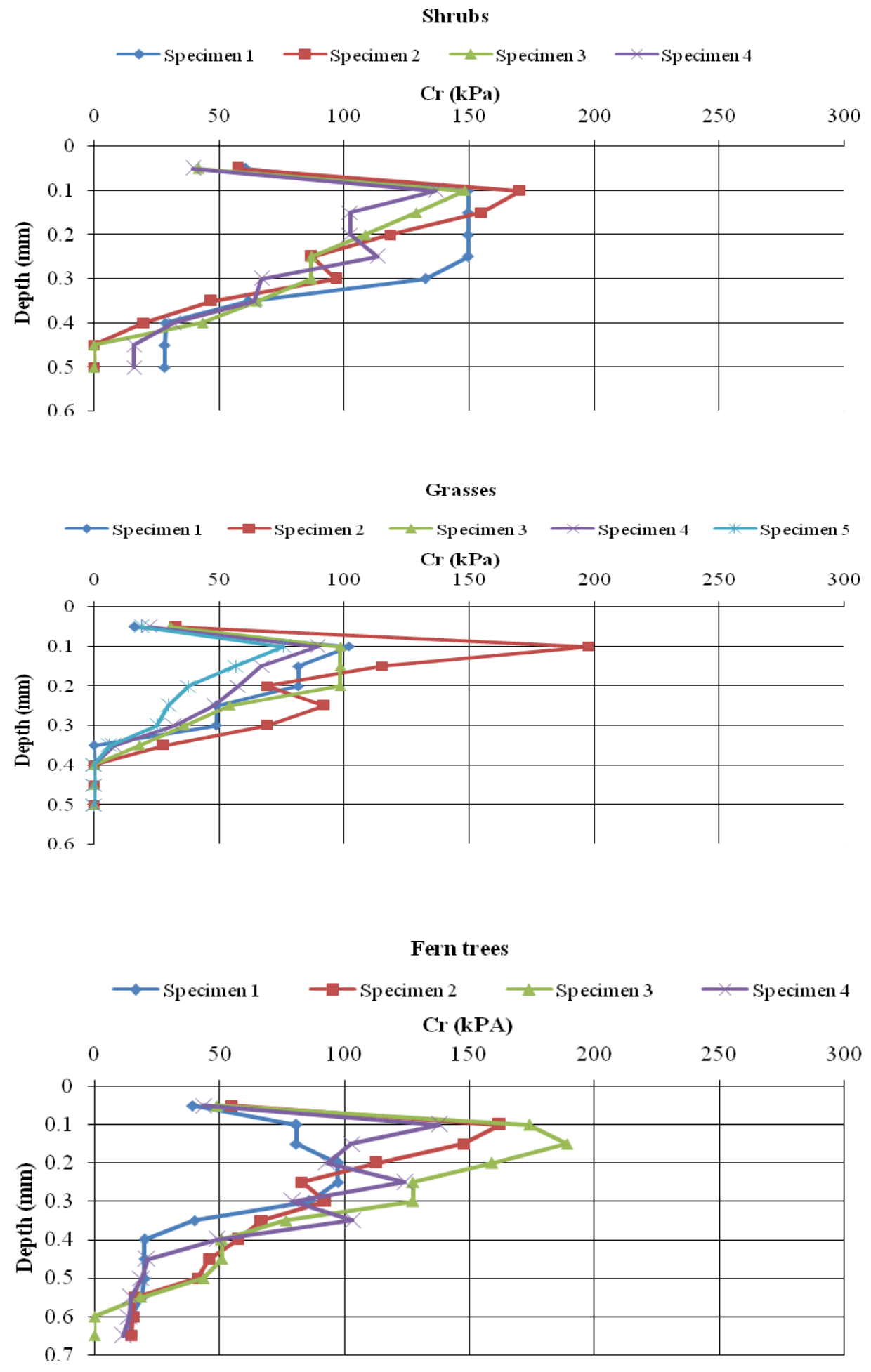

Fig. 8: Cohesion (Cr) distribution with depth by the root system

Similar to the RAR distribution, reinforcement effect decreases with depth. The maximum reinforcement effect exerted by shrubs was $155 \mathrm{kPa}$, for grasses was $197 \mathrm{kPa}$ and for tree ferns 
was $188 \mathrm{kPa}$. High values of cohesion is noted at low depths, explaining why there are shallow landslides occurring at $1 \mathrm{~m}$ depth, where there are no roots to offer sufficient cohesion.

\section{Tensile force-diameter relationship}

The relationship between root tensile force and diameter is linear as shown in Fig 9.
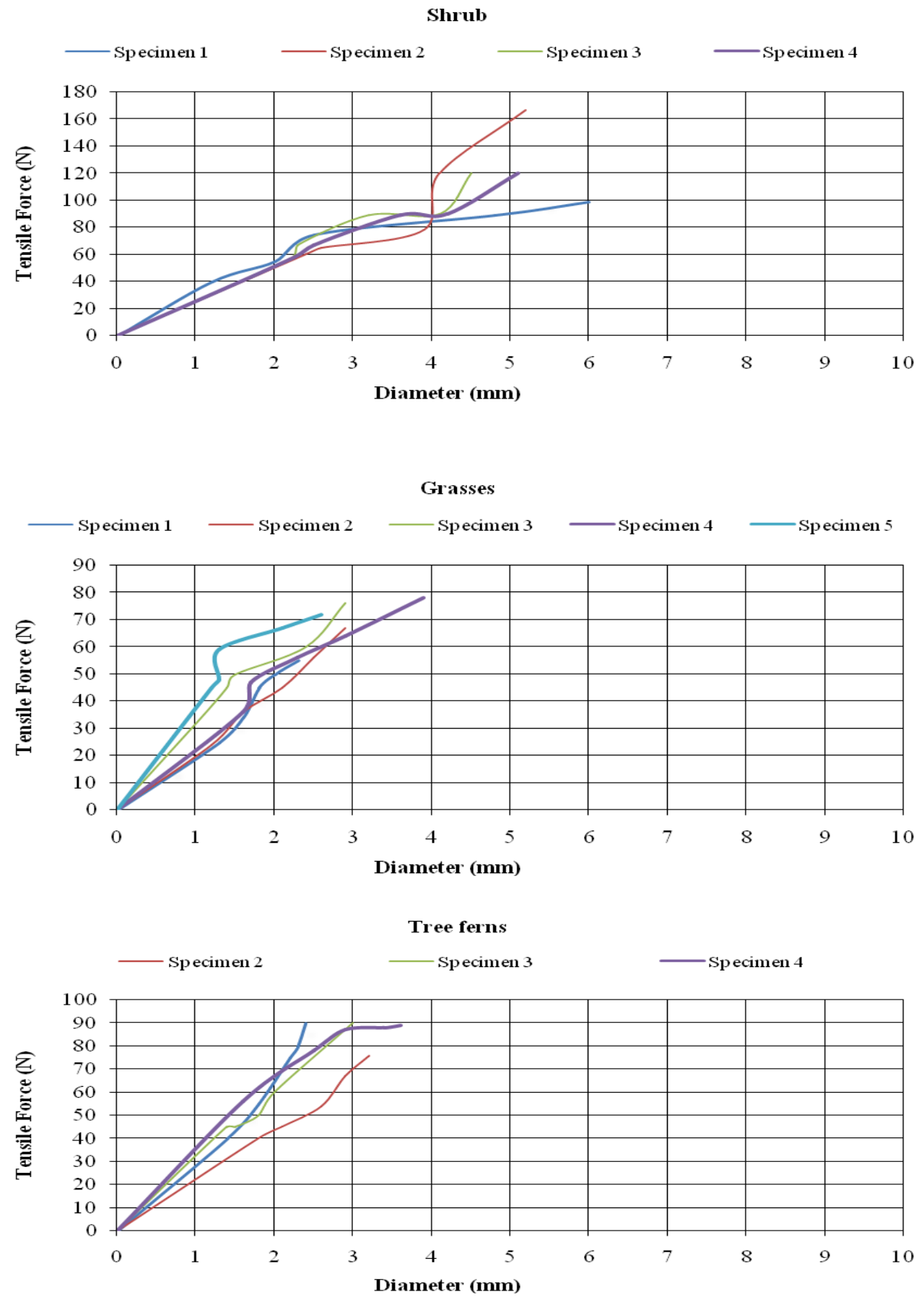

Fig. 9: Tensile force - Diameter relationship for shrubs, grasses and ferns 
Thicker roots fail at higher tensile forces than narrow roots within a similar species. The graphs show that root failure is abrupt after undergoing plastic behavior, explaining why during shear test of root reinforced soils, shear stresses still increase at the end of the test, indicating that root tensile failure do not occur during the shear tests. Root elongation or slippage rather than breakage is thus the most common condition during failure. This mode of failure appears to allow for the survival of certain plant species after a landslide event.

\section{CONCLUSION}

The simple perpendicular model of $\mathrm{Wu}$ was used to calculate soil reinforcement by action of roots. It was observed that, generally, smaller diameter roots have higher tensile strengths, but there was a wide variation in the decline in tensile strengths among individual species. Maximum RAR values were located within $0.1 \mathrm{~m}$ for all the species, with maximum rooting depth of $0.7 \mathrm{~m}$ for fern tree. Shrubs species showed high RAR values between $0.1-0.3 \mathrm{~m}$ depth. In general, vegetations growing in the Backslope have shallow roots (maximum root depth $0.7 \mathrm{~m}$ ) therefore unable to reinforce the soils to stop the landslides occurring at $1 \mathrm{~m}$ depths. Thus vegetation capable of growing deep roots more than $1 \mathrm{~m}$ should be introduced in the Sasumua Backslope to reduce the frequency of shallow landslides occurrence. These vegetations should have high values of RAR, like shrubs or grasses.

Root tensile strength - root diameter relationship depend on plant species. Tensile strength within a species varies by root diameter. Tensile force increases with diameter. Generally shrubs break at high tensile force (160 N maximum), followed by tree ferns (maximum $90 \mathrm{~N}$ ) and lastly grass (maximum $75 \mathrm{~N}$ ). Shrubs have a typically dense and fibrous root system. Tree ferns have a typical tap root system with branching. The general behavior of root density, in any case, is to decrease with depth.

In order to assess the effect of root tensile strength to soil shear strength, the pull-out resistance of a root, which is the measured resistance of root structure to be pulled out of the ground, should be determined and compared to the root tensile strength measured in a laboratory. The relationship between the two can be used to predict pull-out resistance of most species using root tensile strengths.

\section{REFERENCES}

1) Arora D. 1991, All that the Rain Promises and More, Ten Speed Press, Berkeley

2) Bischetti, G.B., Chiaradia, E.A., Epis, T., Morloti, E., 2009. Root cohesion of forest species in the Italian Alps. Plant Soil 324, 71-89.

3) Bougher NL \& Syme K. 1998, Larger fungi of Southern Australia. University of Western Australia Press, Perth.

4) Brundrett MC, Piché Y \& Peterson RL. 1985, A developmental study of the early stages in vesicular-arbuscular mycorrhiza formation. Canadian Journal of Botany 63: 184-194. 
5) Brundrett MC. 1991. Mycorrhizas in natural ecosystems. In: Macfayden A, Begon M \& Fitter AH (eds) Advances in Ecological Research, Vol. 21. Academic Press, London. pp. 171-313.

6) De Baets S., Poesen J., Reubens B., Wemans K., De Baerdemaeker J., and Muys B. (2008), Root tensile strength and root distribution of typical Mediterranean plant species and their contribution to soil shear strength. Plant Soil 305: 207 - 226.

7) Ehsan Abdi, Baris Majnounian, Hassan Rahimi and Mahmud Zobeiri (2009), Distribution and tensile strength of Hornbeam (Carpinus betulus) roots growing on slopes of Caspian Forests, Iran. Journal of Forestry Research, Volume 20, Number 2 / June, 2009

8) Ekanayake J C, Marden M, Watson A J and Rowan D 1997, Tree roots and slope stability: a comparison between pinus radiata and kanuka. NZ J For. Sci. 27(2), 216-233.

9) Gray, D. H., and R. B. Sotir. (1996), Biotechnical and Soil Bioengineering Slope Stabilization. John Wiley \& Sons, New York.

10) Lyr H. \& Hoffmann G. 1967. Growth rates and growth periodicity of tree roots. International Review of Forestry Research 2: 181-236.

11) O'Brien TP \& McCully ME. 1981, The Study of Plant Structure Principles and Selected Methods. Termarcarphi Pty. Ltd. Melbourne.

12) Reubens, B., Poeson, J., Geudens, G., Muys, B., 2007. The role of fine and course roots in shallow slope stability and soil erosion control with a focus on root system aerchitecture: a review. Plant Soil 21, 385-402.

13) Russell RS. 1977. Plant Root Systems: Their Function and Interaction with the Soil. McGraw-Hill Book Co. Ltd., London.

14) Wu, T. H., McKinnell, W. P., III, and Swanston, D. N. (1979), Strength of tree roots and landslides on Prince of Wales Island, Alaska. Canadian Geotechnical Journal, 16(1): 1933. 